\title{
Mulheres mastectomizadas em face do câncer de mama
}

\section{Mastectomized women against the breast cancer}

\author{
Raquel Lopes Gentilli \\ Marilla de Oliveira Moura Nóra*
}

\begin{abstract}
Resumo: O objetivo deste trabalho foi estudar como a mulher mastectomizada se sentem em face do adoecimento e do tratamento do câncer de mama. Tratase de uma pesquisa qualitativa desenvolvida com nove mulheres que sofreram mastectomia num hospital da rede de atenção terciária da cidade de Tubarão/SC. A coleta dos dados ocorreu no domicílio das pacientes por meio de entrevistas semiestruturadas e a análise foi realizada a partir do método história oral de vida tópica. Os resultados apontam que o adoecimento representou sofrimento que poderiam ter sido minimizados a partir da intervenção de uma equipe multiprofissional e interdisciplinar que trabalhasse na recuperação, na promoção da saúde e na articulação entre os diversos cuidados, contribuindo para a reinserção social.
\end{abstract}

Palavras-chaves: Política de Saúde. Interdisciplinaridade. Câncer de mama. Mastectomia. Sofrimento psicossocial

\begin{abstract}
The aim of this study was to know how women with mastectomies felt in the face of illness and treatment of breast cancer. This is a qualitative study developed with nine women who underwent mastectomy in a hospital network of tertiary Tubarão/SC. Data collection occurred in the home of patients through structured interviews and the analysis was performed from the oral history of life topical. The results indicate that the disease represented suffering could be minimized from the intervention of a multidisciplinary and interdisciplinary team that could come to play in the recovery of women with mastectomies, health promotion and coordination between the various care, contributing to the social reintegration.
\end{abstract}

Keywords: Health Policy. Interdisciplinary.Breast cancer.

Recebido em: 30/04/2012. Aceito em: 12/05/2015.

"Assistente Social formada na UFES, Mestre em Ciências Sociais e Doutora em Serviço Social, ambos pela Pontifícia Universidade Católica de São Paulo. Professora do Mestrado em Políticas Públicas e Desenvolvimento Local de Escola Superior de Ciências da Santa Casa de Misericórdia de Vitória, Espírito Santo (EMESCAM). raquel.gentilli@emescam.br

" Graduada em Enfermagem pela Faculdade Univix. Especialista em Enfermagem Cardiológica e Mestre em Políticas Públicas e Desenvolvimento Local, ambos pela EMESCAM 


\section{Introdução}

O Instituto Nacional de Câncer define câncer como sendo o nome pelo qual é referido um conjunto de doenças que têm em comum o crescimento desordenado de células que invadem tecidos e órgãos. Este crescimento pode ser muito agressivo e incontrolável, dando origem a tumores malignos, que atacam determinado órgão e podem migrar para outras partes do corpo. Suas causas são múltiplas e podem ser associadas as de origem interna (predisposição genética) e as externas (ambientes e hábitos que podem agredir o organismo) (BRASIL, 2013).

Apesar de já existir bastante conhecimento acumulado sobre as várias formas de manifestação da doença, bem como seus respectivos tratamentos, ainda existem altos índices de casos de óbitos por câncer, sendo o de mama o principal na população feminina brasileira e o segundo tipo mais frequente na população geral (BRASIL, 2013 b). Embora os anos de sobrevida tenham aumentado para pacientes com tumores diagnosticados e tratados em seus estágios iniciais, o prognóstico para os casos em que a doença já se mostra disseminada no organismo, praticamente não se alterou (BRASIL, 2011). Sabe-se que os cânceres estão fortemente associados a efeitos psicossociais diversos, entretanto a literatura sobre o tema costuma destacar os efeitos devastadores dos cânceres de mama sobre as mulheres pelo fato do mesmo afetar suas percepções sobre a imagem corporal, a sexualidade, a vida social e seu trabalho.

Apesar de já existirem muitas experiências terapêuticas que incluem abordagens psicossociais na atenção a pacientes com câncer de mama, ainda existem centros de tratamentos com recursos terapêuticos no campo clínico e cirúrgico, mas que não oferecem ainda suporte que ajudem as pacientes a desenvolverem expectativas positivas em relação à cura e à qualidade de vida após a cirurgia, conforme preconizado por protocolo já existente desde 2004 (BRASIL, 2004).

Nesse sentido, espera-se que as reflexões aqui produzidas venham contribuir para o compartilhamento de conhecimentos que possam colaborar com o desenvolvimento de estratégias interdisciplinares de tratamento, além de estimular outras pesquisas relacionadas a fatores que afe- tam as relações sociais e de trabalho de mulheres em dificuldades decorrentes de sofrimentos relacionados a mitos, preconceitos e desinformações que produzem diversos impedimentos em sua vida social. Segundo Nóra (2012), para mudar o panorama atual do câncer, é imprescindível que haja estímulo à busca de informações precisas e de qualidade sobre a incidência e prevalência da doença nas populações, propiciando a implantação de políticas públicas que levem à realização de ações efetivas de prevenção e detecção precoce, visando a redução de danos, das taxas de mortalidade e das despesas públicas.

O presente trabalho tem como escopo o estudo da visão das mulheres com diagnóstico de câncer de mama que sofreram mastectomia, no qual se discute a convivência, o sofrimento, as expectativas em relação à vida e ao ambiente social. Pretende-se discutir as dificuldades manifestas por pacientes de assumirem a doença, enfrentarem o preconceito e continuarem lutando por qualidade de vida e saúde. Entende-se que a importância deste estudo está no fato de que tais acontecimentos são considerados difíceis de serem enfrentados, por provocarem uma série de transformações na vida pessoal e social da mulher.

A pesquisa foi realizada na abordagem qualitativa, de natureza exploratória visando conhecer a realidade social e afetiva de mulheres que realizaram cirurgias de câncer de mama durante o ano de 2010, em um hospital da rede conveniada de serviços de alta complexidade do Sistema Único de Saúde (SUS) de Tubarão, no Estado de Santa Catarina.

A amostra foi aleatória e identificada entre as pacientes que fizerem mastectomia no ano de 2011 e que aceitaram ser entrevistadas, sendo consideradas as diferentes faixas etárias nas quais a doença tem acometido as mulheres; que não tinham comorbidades associadas, residentes na cidade e que aceitaram assinar o Termo de Consentimento Livre e Esclarecido.

Antes de se chegar às entrevistadas foi realizado um estudo em prontuários, onde foram identificadas 87 (oitenta e sete) mulheres que sofreram os diferentes tipos de mastectomia no referido hospital, sendo que 45 (quarenta e cinco) residiam na cidade de Tubarão, Santa Catarina. Para as entrevistas, foram selecionadas pelos critérios de inclusão, apenas aquelas que haviam

338 Emancipação, Ponta Grossa, 14(2): 337-348, 2014. Disponível em <http://www.revistas2.uepg.br/index.php/emancipacao> 
sofrido mastectomia total, radical ou radical modificada e que aceitassem participar da pesquisa. Entre estas,apenas 9 (nove) foram entrevistadas.

Metodologicamente foi realizada a abordagem da história de vida oral tópica. Considerando a sugestão de Meihy e Holanda (2007), foi utilizada a entrevista semiestruturada, baseada em expressões dinâmicas e abrangentes do vivido, por meio de narrativas pessoais, onde foram abordados episódios específicos sobre a vida das pacientes. A história de vida oral tópica, segundo os autores, está ligada à forma como o pesquisador busca a colaboração para a produção da fala do entrevistado. Na história oral de vida tópica, diferentemente da história de vida tradicional, é o pesquisador quem define os temas e conduz a abordagem, controlando o entrevistado mais prolixo e impondo limites ou cortes quando absolutamente necessários.

Apesar disto, não deixa de estimular a narrativa livre e espontânea e atenta aos cuidados éticos para garantir ao entrevistado o espaço para que sua história seja encadeada, segundo sua vontade e condição. Durante as entrevistas, a pesquisadora realizou perguntas que tinham sido previamente elaboradas com o objetivo de estimular os depoimentos e que tinham sido validadas num pré-teste realizado anteriormente.

$O$ agendamento das entrevistas foi providenciado previamente, segundo a conveniência das entrevistadas que decidiram por local, horário e data. Também foi solicitado consentimento para gravar as entrevistas, a fim de garantir a fidedignidade da base de dados da modalidade técnica escolhida, sendo assegurada a cada uma das entrevistadas que poderiam interromper a entrevista a qualquer momento.

Antes de iniciadas as gravações foram registrados os dados de identificação das entrevistadas (nome do projeto, data, nome do entrevistador, pseudônimo escolhido pela entrevistada e local da entrevista). Após a entrevista, o relato oral foi transformado em texto escrito.

Ao término de cada entrevista, foram realizadas as seguintes etapas da proposta metodológica de Meihy e Holanda (2007): 1) transcrição literal de todas as palavras e sons que foram pronunciados na ocasião da entrevista, diferenciando as falas ou perguntas do entrevistador das respostas do entrevistado; 2) textualização, correspondente à supressão das perguntas fei- tas pelo entrevistador, passando a elaboração de composição de um texto escrito de maneira uniforme, e a 3) "transcriação", uma recriação do texto, mantendo os sentidos da fala inicial das entrevistadas, sem intervenção da pesquisadora nas situações relatadas, porém reordenando os dados, a fim de propor melhor clareza na exposição dos fatos. Após leitura de cada depoimento, os conteúdos foram agrupados e aprofundados para a realização da presente análise.

\section{Adoecimento feminino por câncer de mama}

Apesar de o Brasil se dedicar a estudos epidemiológicos sobre o câncer desde a década de 1920 - e hoje contar com uma rede de instituições especializadas em pesquisa, atenção e prevenção dos diversos tipos de cânceres existentes -, o adoecimento por câncer vem sempre acompanhado de medo, preconceito e representações carregadas de mistérios e dúvidas, sobretudo pelo fato dos mesmos possuírem etiologias diversas, multicausais, imprecisas e de evolução silenciosa.

Percebe-se que, apesar de muitos tratamentos exitosos, com cura se descoberto precocemente, o câncer, em geral, ainda assusta muito. No caso do câncer de mama, pacientes e suas famílias possuem dificuldades de se adaptarem aos diversos estágios impostos pelo tratamento; fator que contribui para a exacerbação de reações e sentimentos.

A questão se agrava ainda mais quando a doença se encontra em fase de tratamentos mutiladores que podem provocar diversos impedimentos como eventuais interrupções das atividades profissionais ou dos cuidados da casa e dos filhos, alterando significativamente as atividades cotidianas anteriores.

O prognóstico relativamente bom do câncer de mama está associado a múltiplos fatores como adoção de políticas que atendam a alguns requisitos fundamentais ligados ao diagnóstico precoce, tratamento adequado em tempo hábil,acessibilidade da paciente à assistência qualificada o mais rápido possível após detecção do tumor, educação permanente de profissionais de saúde no atendimento eficiente e humanizado,garantia da execução da política de atenção oncológica de acordo com os princípios da integralidade, da universalidade e do reconhecimento de que o cuidado de saúde consiste num 
direito do cidadão e num dever do Estado. Para garantir uma atenção tão complexa e diferenciada há que se ter uma atenção especial na formação e constituição das equipes de saúde, buscando a construção de uma abordagem interdisciplinar e integrada à experiência das usuárias (BRASIL, 2008).

Os cânceres apresentam várias formas de etiologia e desenvolvimento. Pivetta (2004) identificou que a incidência do câncer aumentou por causa do estilo de vida do homem moderno que convive mais com fatores de risco como o fumo, a exposição ao sol em excesso, ao hábito de beber demais e ter contato prolongado com produtos químicos potencialmente carcinogênico ou a determinados vírus. Existe ainda a associação do câncer a causas genéticas, já que 15\% das mesmas são relacionadas à hereditariedade.

A elevação da incidência da doença também está relacionada à melhoria dos processos de identificação das mesmas, devido ao progresso do conhecimento científico assim como à maior informação sobre a doença. Estes fatos ajudaram tanto no diagnóstico precoce de vários tipos de câncer, como no aumento dos registros estatísticos de casos de mortes atribuídas a ele. O aumento da população idosa também tem contribuído na mudança do perfil epidemiológico, possibilitando o impacto das neoplasias no cenário do adoecimento mundial (VERAS, 2007).

Xavier e Gentilli (2012) registram ainda que o adoecimento de câncer de mama atinge não só as mulheres, mas também as relações familiares como um todo, aumentando os sofrimentos de origem social e afetivos de todo grupo familiar. Este fato decorre da necessidade de toda a família, além das pacientes, necessitar de tempo para assimilar subjetivamente a dor e as limitações da doença, das dificuldades de relacionamento com o hospital, com os exames a serem realizados e com a equipe médica.

Nesse caso, observa-se que os aspectos sociais vinculados à vida familiar, aos amigos e às relações sociais em geral acabam interferindo nas situações de sofrimento e na busca de atitudes de aceitação em relação às mudanças que o câncer de mama provoca nas pacientes. A mulher, principalmente a de baixa renda, tem toda a sua vida comprometida pelo adoecimento, principalmente quando provedoras da família.
O que se pode observar com base nas discussões recentes é que, dada a complexidade social dos adoecimentos, o tratamento também precisa observar os vários aspectos clínicos, psicológicos e sociais das pacientes e de seus familiares. Nesse contexto, a família pode se constituir numa fonte de apoio, tornando-se fundamental para que a mulher enfrente todo o processo de adoecimento, quanto pode se constituir em origem de angústia, tornando os caminhos mais penosos e sofridos. Tudo depende da capacidade desta conseguir se manter unida durante todo o processo.

Pesquisas recentes buscam conhecer os efeitos da intervenção da equipe interdisciplinar na recuperação no sistema imunológico em mulheres com câncer de mama. Ader e Cohen (1991) identificaram que a psiconeuroimunologia (PNI)- um campo de estudo da consciência (psico), do sistema nervoso central (neuro) e das defesas do corpo contra infecções extensas ou de divisão celular aberrante (imunologia)-, tem tornado possível melhorar a compreensão dos complexos fatores que incidem sobre o adoecimento por câncer.

Esta abordagem estuda a influência dos estados psicológicos na função imune e nos sistemas nervoso e endócrino. Tais estudos, de natureza interdisciplinar têm dado origem a dados substanciais que suportam a hipótese de stress-doença, associando avaliações dessa relação com implicações práticas em todas as fases da assistência primária, secundária e terciária do câncer de mama (AMORIM,1999).

A partir dessa concepção, tem-se observado que, para intervenções mais eficientes nas diversas fases da doença, a própria equipe precisa acreditar que sua intervenção é de extrema importância para a recuperação do sistema imunológico e do estado emocional da paciente, envolvendo, desta forma, os diversos aspectos da vida da pessoa que adoece e da qualidade dos serviços oferecidos.

Algumas experiências de acompanhamento de pacientes que se encontram em tratamento de câncer em ambulatórios, visando apoiar as pacientes a suportarem o processo de adoecimento envolvem, inclusive, atividades lúdicas, reflexivas e práticas médicas alternativas e complementares, além de buscarem influenciar positivamente sobre suas experiências futuras. Tais

340 Emancipação, Ponta Grossa, 14(2): 337-348, 2014. Disponível em <http://www.revistas2.uepg.br/index.php/emancipacao> 
estratégias funcionam como grupo de apoio para reverter expectativas em face do adoecimento, mobilizando-as a assumirem ativamente o próprio processo de cura da doença, o enfrentamento de tabus e de preconceitos, envolvendo-as no investimento físico, social e emocional.

\section{Significados sobre o câncer de mama e a mastectomia}

Conforme foi observado por Amorim (1999), predomina entre a clientela que recebe atendimento para tratamento de câncer, mulheres que se encontram na faixa etária de 51 a 60 anos; com escolaridade limitada, geralmente com ensino fundamental incompleto; procedente geralmente de cidades do interior, onde o acesso aos serviços especializados é mais difícil, geralmente chegam aos hospitais de referência sem diagnóstico e sem tratamento e já no estádio II de evolução da doença. Entretanto, ocorre o acometimento da doença em pessoas bem mais jovens e até em idades mais avançadas.

O câncer de mama, apesar dos progressos da medicina em relação aos métodos de diagnóstico e tratamento, para muitas mulheres, ainda é visto como uma doença cruel e estigmatizante, que consome o indivíduo aos poucos. O impacto da notícia é muito importante para a pessoa adoecida e seus familiares. A mulher pode se sentir frágil, temerosa e necessitar de ajuda.

O câncer de mama representa uma ameaça em vários níveis. Os efeitos deletérios dessa doença têm preocupado os profissionais de saúde envolvidos com a qualidade de vida dessas pacientes. Sontag (1984) já identificara que as várias visões construídas e partilhadas socialmente, ao longo da história a respeito do câncer, contribuíram para que essa doença ainda fosse vista como uma sentença de morte.

Verificou-se entre as mulheres a frequência de relatos dramáticos sobre a percepção de felicidade/infelicidade relacionada ao fato de terem adoecido e sofrido uma cirurgia radical de mama. As entrevistadas se referem ao sofrimento com a doença, associando tristeza, sensação de terem sido castigadas, revolta com o ocorrido, expectativa de morte e desespero. São sentimentos muito fortes que aparecem sempre nas falas de todas.

Segundo Boff (1999), o câncer de mama é um acontecimento marcante com implicações sociais, psicológicas e sexuais. O câncer de mama representa uma ameaça em vários níveis. Dependendo do contexto em que o processo de adoecimento ocorra, os desdobramentos psicossociais podem ser mais ou menos drásticos. As falas e visões tratam de temas em relação ao diagnóstico, ao momento da mastectomia, à convivência familiar e social, às expectativas em relação ao tratamento e à cura. Pode-se observar que relatos sobre as dificuldades em relação ao adoecimento, estão associados também a questões que envolvem a convivência com as demais pessoas, 0 que inclui seus respectivos companheiros. Foram identificadas reações de afastamento de amigos e da convivência social, que remetem à tristeza, solidão e medo do olhar do outro:

Distanciei-me um pouco dos amigos, até porque no começo tinha vergonha! (Orquídea, 53)

Eu sentia solidão, tristeza, queria ficar isolada, quietinha no meu canto! Não gosto nem de lembrar! (Sol, 38)

Você não tira mais o sutiã perto de ninguém, você não troca de roupa perto de ninguém, você acha que alguém vai perceber, vai ficar olhando. (Valéria, 58)

Entre as atitudes declaradas pelas entrevistadas aparecem o recolhimento e o isolamento social, que levava à solidão e provocava tristeza. Revelam-se afetadas pela vergonha do corpo nu na intimidade e até da roupa que utilizam para disfarçar a mutilação. Sofrem com uma autoimagem estigmatizada, que as levam a esconder o corpo. A vergonha e o isolamento são sentimentos já identificados há certo tempo em outras pesquisas, conforme as reflexões de Rzeznik e Dall'agnol (2000).

Desde a década de 1940, as mutilações fazem parte do enfrentamento ao câncer e afetam particularmente mulheres com câncer de mama. Tal situação tem sido atribuída ao fato da mama ser um dos principais símbolos da feminilidade por vários autores. Pode-se também pensar na questão da estética, associada ao estereótipo do que seria um corpo feminino e sua beleza, assim como ao corpo íntegro e em condições de trabalho, associado ou não à vaidade feminina.

O impacto do diagnóstico de câncer de mama é influenciado pelo contexto sociocultural 
no qual o indivíduo está inserido, por interferir no seu comportamento e em suas atitudes quando da descoberta, ao longo do tratamento e posteriormente na retomada da vida social. São as experiências sociais e culturais que vão influenciar nas crenças que as mulheres vão desenvolver a respeito do câncer de mama, cujos significados são formados ao longo da vida, de modo especial em suas interações familiares e sociais (FERNANDES e MAMEDE, 2003).

Estas podem estar relacionadas à forma como cada sociedade lida com as expectativas dos desempenhos dos papéis femininos de mãe, esposa e até de provedora da família, e ainda como lida com o processo saúde e doença. Dependendo do que está sendo posto em questão na vida da mulher, os danos provocados pelas cirurgias mutilantes, podem ser sentidas como mais ou menos devastadores pelas mulheres mastectomizadas.

Foi possível observar, entre as pacientes diagnosticadas com câncer de mama que, tanto o diagnóstico quanto o tratamento e suas sequelas são muito difíceis de serem vividas. Relataram desorientação em face da mudança em sua qualidade de vida, de desalento pela mutilação, pela modificação do corpo, do sentir-se exposta à chacota do outro, conforme algumas falas apontam:

Depois que descobri que tinha câncer, foi muito triste. Meu chão saiu! Fiquei pensando: Porque comigo? O que eu fiz? O que vai me acontecer? (Girassol, 52)

É muito ruim. Eu sinto vergonha! A gente não sai porque não se sente bem, deixa as amizades. Porque por mais que a gente bote 0 sutiãzinho de bojo, está sempre desconfiada de que alguém está olhando, rindo. É assim. Fico o tempo toda incomodada! (Valéria, 58)

Tem um peito, o outro não tem. Não dá para você olhar no espelho, sabe? Na verdade, acho que tenho receio de olhar no espelho, a imagem me assusta. Eu estou deficiente. (Orquídea, 53)

O câncer, depois de instalado, mesmo tratado, se torna uma ameaça constante para maioria dessas mulheres. Sentem-se vulneráveis em face de um eventual retorno da doença. Verificamos que entre as nove pacientes entrevistadas, sete dessas vivem preocupadas e com medo do re- torno da doença. Apesar deste temor, de um lado provocar muito mal-estar, por outro lado, o próprio fato em si pode provocar mudança positivas em suas vidas.

Por mais surpreendente que possa parecer, ainda existem histórias de pacientes que afirmam viver em função da família e da responsabilidade pelo provimento da mesma, a ponto de negligenciarem a própria saúde e o cuidado de si mesmas, comprometendo, por vezes, a terapia recomendada pela equipe de saúde.

Segundo Silva et al (2010), o temor pela reincidência da doença faz com que elas tomem consciência da necessidade de mudar os hábitos de vida, situação que se reflete na declaração de que passaram a tomar mais cuidado com a saúde delas próprias. Pelas falas fica a impressão de que a vida ganha novo significado. Das entrevistadas, quatro esboçam raciocínio nessa direção:

Muda tudo! Sua vida, sua maneira de ver as coisas, sua forma de pensar, de valorizar a vida, as coisas. Eu faço o que quero, e penso em mim também. (Orquídea, 53)

Muda seu jeito, as pessoas que estão com você, sua forma de olhar a vida, de se comportar, de agir. Tudo muda. Valorizo mais minha vida, minhas coisas. (Sol, 38)

Com tantas dificuldades sociais e pessoais a serem enfrentadas pelos problemas inerentes ao tratamento, essas mulheres precisam de informações sobre todas as etapas do adoecimento, do diagnóstico à reconstrução da mama e que, nem sempre o hospital está preparado para cuidar, informar e orientar sobre direitos, o processo de tratamento e nem como contornar as dificuldades reais. Muitas vezes o processo de trabaIho hospitalar parcelado, corrido, burocratizado, impõe uma rotina aos profissionais que causam estranhamento às pacientes, pela desinformação, desorientação, frustração e abandono. Foi possível identificar nos relatos algumas queixas nesse sentido, revelando que tais necessidades de mais informações são muito importantes para elas:

As pessoas me atenderam bem, mas não me deram muita atenção. Não tive nenhuma orientação! De ninguém! (Maria, 52)

Eu queria ter mais informações. Quando fiz a cirurgia, eles só falam assim: "Agora tu vais tomar esse remédio aqui, que é um hormônio, 
por cinco anos". E você não sabe que hormônio é esse, para que ele serve como ele age, o que ele faz. Eles não me falaram. Faltou informação. (Sol, 38)

No hospital eles falam rápido algumas poucas coisas e só. Depois é só mesmo o que você pergunta nas consultas. (Orquídea, 53)

A falta de informação sobre o prognóstico da doença pode ser considerada uma abordagem inadequada do problema, sobretudo num contexto em que já existem experiências bem-sucedidas que contam com grupos de apoio para que as pacientes possam elaborar coletivamente problemas e percepções comuns, que muito vem ajudando numa abordagem mais totalizante do sujeito.

Algumas mulheres conseguem determinar novas perspectivas de vida, ultrapassarem as limitações da doença, reintegrarem-se e superar as dificuldades inerentes ao adoecimento; entretanto, outras não conseguem se adaptar a essa nova realidade, que parece afetar profundamente suas identidades pessoais, levando a um adoecimento mental como depressão e a uma sensação constante de vergonha, invalidez e mutilação, conforme exemplos abaixo:

Quando tive o diagnóstico foi horrível. Procurei ajuda para me tratar. Tomo remédio para depressão até hoje (Valéria, 58)

Ainda para mim é muito difícil! Me incomoda bastante. Tirar a mama é complicado. Sempre tem vergonha. (Árvore, 61)

Parece que você tira só um pedacinho, mas é tanta coisa! Só quem tira para saber. (Orquídea, 53)

Pode-se registrar ainda que a doença, seu tratamento e suas sequelas desencadeiam sentimentos e emoções fortes. A ausência de informação e de acompanhamento e de orientações sobre as possibilidades de recuperação provocam imobilização, expressas muitas vezes por sentimentos fortes como medo, raiva, tristeza e solidão:

Raiva, desespero quando o cabelo caiu, solidão, dor! (Orquídea, 53)

Revolta, medo, angústia, tristeza! Para mim a parte mais difícil foi a quimioterapia. Além da tristeza, eu tinha muita náusea! (Árvore, 61)
Raiva, medo, dor. Chorei muito. O que foi mais difícil foi fazer aquela quimioterapia. Foi de matar. Criei um cascão grosso na língua, não comia, não dormia, o cabelo caiu todo, todo, todo. (Valéria, 58)

O câncer, em nossa sociedade, está relacionado à crença de que seu portador está condenado a morrer. Este estigma é histórico devido às poucas chances de cura que um paciente oncológico dispunha tempos atrás, com técnicas cirúrgicas extremamente mutiladoras e ausência de tratamentos adjuvantes eficazes. Caetano, Gradim e Santos(2009), observam, porém, que com o avanço da tecnologia na área médica e nas novas abordagens de tratamento, essas pacientes passam a ter maiores chances de reabilitação e de retomada de suas vidas cotidianas, apesar deste horizonte parecer distante para muitas.

Goffman (1988) numa obra clássica sobre o estigma, afirmara que o indivíduo estigmatizado acaba sempre enfrentando novas crises diante de situações que mencionam sua condição. Nos casos dos significados atribuídos ao câncer podem afetar profundamente a maneira como a mulher percebe sua doença, bem como as respostas de outras pessoas em relação a sua nova condição.

Para a mulher mastectomizada, as limitações impostas pela intervenção cirúrgica refletem diretamente na necessidade de realizar novos papéis e tarefas profissionais, bem como nos seus afazeres domésticos. Em face da nova situação de vida, passam a enfrentar limitações sociais e terá que abrir mão de suas atividades rotineiras. Das nove entrevistadas, oito deixaram seus empregos e restringiram suas atividades a domésticas, como nas ilustrações abaixo:

Não dá para trabalhar mais fora de casa. Até dentro de casa é difícil. Ás vezes tem que arrumar devagar... um quarto; parar; arrumar o outro; parar.... É assim! O braço dói muito, incha. (Girassol, 52)

Interferiu porque eu fiquei sem resistência! O braço dói, incha! Aí eu parei de trabalhar e agora estou tentando na justiça me aposentar. (Rosa, 45)

O braço fica sem força. Ele não é mais o mesmo. Ele fica pesado e dificulta fazer suas tarefas. Da dormência. Até para escrever é difícil. (Árvore, 61) 
Araújo e Fernandes (2008) atribuem a estas dificuldades físicas os motivos que contribuem para acelerar o comportamento depressivo e o isolamento social das pacientes que sofreram mastectomia por não desempenharem mais as tarefas da mesma forma que antes ou por se sentirem diferentes e inúteis, comprometendo suas relações pessoais e também as de amizade.

Querem se desfazer o mais rapidamente possível da doença, entretanto, quando as sequelas surgem, comprometendo a relação com o trabalho, a vida social e a aceitação de parentes e amigos, a aceitação inicial se transforma em sensação de vazio. A queda de cabelos acaba expressando essa dificuldade. Todas as que fizeram quimioterapia e perderam cabelos, nenhuma delas tirou fotografias enquanto estava sem cabelo, somente depois que o cabelo crescer novamente.

As mulheres que realizaram a mastectomia expressaram ainda um sentimento de ambivalência sobre o procedimento cirúrgico. Aceitam a retirada da mama porque acreditam que após esse procedimento ficarão curadas e esperam não precisar mais se preocupar. Entretanto, ao mesmo tempo, sentem-se frustradas ao se depararem com um corpo que já não é mais o mesmo e que se encontra mutilado. Neste caso, o abandono de si mesma e até em seus companheiros pode ocorrer:

Depois que me deu isso [câncer de mama], ele [marido] se afastou de mim. Ele foi saindo assim aos poucos da minha vida. (Valéria, 58)

Não tem jeito de fugir da cirurgia. Eu tenho medo do câncer porque ele pode ir para outro lugar. Os médicos que façam o que acharem melhor, só quero ficar curada. (Árvore, 61)

A gente acaba se acostumando porque não tem jeito de fazer nada, a gente só quer ficar curada. (Flor, 48)

King et al (2000) observaram ainda que o impacto da mastectomia sobre a imagem corporal é maior em mulheres casadas do que em mulheres solteiras e Cohen et al (2000) acrescentam que mulheres mais jovens (casadas ou solteiras) têm maior dificuldade de adaptação após o diagnóstico da doença e da mastectomia. Essa situação é agravada pelo abandono de alguns maridos e companheiros.Algumas ao se referirem a relações sexuais falam de se sentirem inibidas e tentam ocultar a mama mutilada.

Segundo Kenny et al (2000), observaram, entretanto, que mulheres mais velhas apresentam melhor escore de qualidade de vida porque valorizam menos a mama e a feminilidade. Pode-se observar que tendencialmente, pode-se supor que o câncer de mama vai interferir mais ou menos na vida da mulher, segundo sua faixa etária e sua disponibilidade para uma vida sexual mais ou menos ativa, sendo melhor aceita pelas mulheres mais velhas.

Para Duarte e Andrade (2003), as sequelas emocionais ou sociais existentes decorrem da mudança na autoimagem e na forma como entendem, sentem e interpretam o mundo a partir da experiência. Assim, dificilmente a mulher que passa pela experiência do câncer de mama, retoma sua vida anterior normalmente, podendo perdurar o sofrimento durante muitos anos.

\section{Equipe interdisciplinar e a melhoria na qualidade de vida}

O Documento de Consenso para o controle do câncer de mama (BRASIL, 2004) preconiza que as ações junto a pacientes e familiares devam ser de natureza interdisciplinar e significar um esforço da equipe desde o diagnóstico, visando favorecer o retorno da paciente as suas atividades físicas, sociais e profissionais, o mais rápido possível. Espera-se que a intervenção da equipe composta por médico, enfermeiro, psicólogo, fisioterapeuta, terapeuta ocupacional, assistente social e nutricionista - sendo cada profissional responsável pelas condutas em sua área de competência -, deva ser precoce, desde o diagnóstico inicial, acompanhando o tratamento até a doença avançada, quando for o caso. Em eventos com diagnóstico de impossibilidade de cura, a equipe deve agir no sentido de estabelecer procedimentos de cuidados paliativos, visando garantir a melhor assistência possível para pacientes e familiares.

Em conjunto, a intervenção interdisciplinar deverá ser realizada por orientações domiciliares, tratamento ambulatorial, tratamentos hospitalares específicos e grupos de apoio de educação em saúde, envolvendo diversas especialidades que devem garantir o acesso às informações relacionadas aos direitos previstos em lei a uma 
atenção integral. Algumas ações que envolvem estratégias de fortalecimento do controle social, de mobilização de projetos sociais que visem à humanização da saúde - ações mais de natureza sociopolítica e socioinstitucional -, são atividades nas quais os assistentes sociais podem exercer um papel estratégico para garantir o êxito de toda a equipe.

Além das estratégias terapêuticas, há que se ter um eficiente controle social e científico no monitoramento das ações e da incidência dos casos, de preparação da equipe, dos conselheiros de saúde e da população através da educação em saúde de forma continuada. Estes são procedimentos de gestão fundamentais para a promoção da saúde, tendo em vista a humanização da assistência na perspectiva do respeito aos direitos humanos das pacientes. Em articulação com as organizações da sociedade civil, ações de saúde podem ser realizadas desde o diagnóstico precoce, até a reconstrução mamária, ampliando as formas de divulgação de informações sobre o câncer de mama.

Devido a estas questões, a assistência prestada às clientes deve privilegiar a elevação da qualidade de vida, a assistência social, o esforço para elevação da autoestima e a busca por novas atividades profissionais que venham contribuir com a melhoria das condições de vida como um todo. Dessa forma, a assistência interdisciplinar deve estimular as mudanças nos aspectos psicossociais, assim como a readaptação no estilo de vida e de trabalho da mulher.

O trabalho em equipe multiprofissional pode dar suporte para contribuir de forma significativa para a qualidade de vida dessas mulheres. Assim, o trabalho da equipe com a mulher com diagnóstico de câncer de mama deve ajudá-la a estabelecer novos propósitos na vida e integrar seu novo ser de forma produtiva e saudável, deve ser estimulada a ter esperança de voltar à normalidade, tornando-se, nesse sentido,um importante fator facilitador no enfrentamento das situações de crise que são comuns no processo de adoecimento e de tratamento de câncer.

Para esta mulher é fundamental compreender a doença e seus significados, bem como as consequências sociais para si, sua família e amigos. Ser capaz de refletir sobre o papel que exerce na vida diária da família, em suas relações pessoais, sociais e de trabalho torna essa mulher mais predisposta a cuidar de si e de seus entes queridos, de retomar tão logo quanto possível o convívio social, bem como descobrir novas maneiras de ter uma melhor qualidade de vida.

A reconstrução mamária é uma opção para melhorar a qualidade de vida da mulher submetida à mastectomia, pois pode atenuar o impacto emocional e físico provocado pela cirurgia radical, e tem como objetivo imediato a reparação da mutilação da mastectomia; restaurando a forma e o volume da mama amputada, preservando assim a autoimagem da paciente; contribuindo para a recuperação psicossocial mais rápida.

Entretanto, muitas vezes, as mulheres criam uma expectativa enorme com essa cirurgia e acham que terão novamente sua mama como anteriormente, e não é bem assim que acontece. Forma e volume da mama são reconstituídos, mas a parte estética nem sempre fica tão boa conforme as expectativas, recolocando novas frustrações e novos conflitos. Fica claro que, algumas mulheres são afetadas em seus domínios emocional, social e sexual, não somente no período do início do tratamento, podendo se estender por um longo tempo após o diagnóstico, sugerindo que os cuidados devam ser oferecidos à paciente após o término do tratamento, sem previsão de alta (HOLZNER et al, 2001).

Segundo Anderson (2008), a atenção primária ainda é muito importante no sentido de começar as ações para a promoção da saúde através da educação, da prevenção, preparando os pacientes para uma melhor recuperação e reabilitação dos problemas mais recorrentes de saúde. Para que esse aprendizado seja socialmente possível, a equipe interdisciplinar precisa criar condições para que seja facilitado o acesso à rede de serviços, aos direitos sociais e aos socioassistenciais, quando necessários. A equipe precisa também consolidar uma atuação de forma interdisciplinar e em articulação com as demais políticas de seguridade social visando à superação da fragmentação dos serviços e do atendimento, cujo trabalho profissional do assistente social é imprescindível.

\section{Conclusão}

Após analisar atentamente as entrevistas, pode-se concluir que as emoções, quase sempre associadas ao medo da morte e desespero, já 
haviam sido desencadeadas desde que tiveram acesso ao diagnóstico. Tais emoções constituem dificuldades reais ou imaginárias que vão acompanhar a cirurgia mutiladora, o tratamento complementar e a reconstituição da mama.

A cirurgia aparece como o pior momento das experiências relatadas, apesar da forte expectativa de terem suas vidas salvas. Em face da cirurgia e da possibilidade de resolver o problema de saúde o mais rápido possível, as mulheres se submetem ao tratamento porque desejam a cura.

Apesar disso, para algumas entrevistadas, revelou-se difícil conviverem diariamente com a possibilidade de morte, associada a ideias socialmente difundidas sobre o câncer de mama. $O$ fato da aceitação momentânea do tratamento e das mudanças provocadas pelo câncer de mama e da nova forma de viver a vida, não significa que continuará aceitando facilmente os demais tratamentos necessários.

Posteriormente, vem a fase de retomada de seus cotidianos. Só neste momento em que os relacionamentos sociais, atividades de lazer, trabalho e família são retomados, é que surgem as preocupações relacionadas ao próprio corpo. Através dessas relações sociais é que ocorre um confronto das mulheres com a realidade, fazendo com que elas passem a avaliar e reelaborar as suas ações e as formas de relacionar-se com o próprio corpo e com os outros.

Para se adequarem a uma nova situação e, em particular, à perda da mama, empenham-se de certa forma, em todos os âmbitos de suas vidas, alterando também relações afetivas e sociais, que passam a ser refletidas nas formas como percebem a si mesmas e nas formas como vivem suas vidas. Esse processo faz com que elas possam melhor elaborar suas ações e formas de se relacionar em consigo mesmas e com os outros. As alterações do próprio corpo implicam também em transformações afetivas.

Segundo os depoimentos, o mais difícil para as mulheres entrevistadas foi a constatação de que o tratamento de câncer de mama é longo, na realidade um processo terapêutico que envolve exames clínicos, mamografia, ultrassonografia, cirurgia e os demais procedimentos terapêuticos como a quimioterapia, a radioterapia e a hormonoterapia, dependendo do caso. Depois da alta, ainda existe a necessidade de controle frequente e muitas vezes de uso de medicamentos por um longo tempo. Todo esse conjunto de ações de saúde envolve um conjunto de procedimentos que levam tempo para serem assimilados pela mulher e seus familiares.

No caso específico da região onde foi realizado o estudo, percebe-se que a forma como o serviço lida com as pacientes precisa ser meIhorado em relação à prestação de informação a respeito da doença, da cirurgia, do tratamento, dos cuidados adjuvantes como grupo de apoio ou programa de reabilitação voltado as mulheres mastectomizadas, para que possam ser ampliadas as expectativas e a qualidade de vida das pacientes na cidade, conforme preconiza o documento de consenso de 2004.

O suporte que uma equipe interdisciplinar, composta por médicos, enfermeiros, psicólogos, assistentes sociais e fisioterapeutas capacitados poderia contribuir, não só para a redução das consequências associadas ao estresse, à ansiedade, ao medo e à insegurança provocada pelo tratamento, pela cirurgia, pela possibilidade de retorno da doença e até mesmo pela preparação para a reconstrução da mama; mas também para oferecerem situações apoio e acolhimento para influenciar positivamente na recuperação da mulher mastectomizada, na promoção da sua saúde, na articulação entre os diversos cuidados e contribuir para sua reinserção social. Afinal, segundo Nóra e Gentilli (2012) cada mulher reage a essas situações conforme algumas variáveis que dizem respeito à sua história de vida, ao contexto social, econômico e familiar de cada uma.

Os relatos aqui trazidos apontam para a necessidade de melhoria da qualidade de vida destas mulheres, e consequentemente de suas próprias visões sobre a recuperação de um adoecimento por câncer, e isso se torna possível com a implantação de medidas preconizadas pelo documento de consenso de 2004, pela descentralização da assistência à saúde, pelo acesso aos exames, tratamentos, atendimentos e informações sobre os cuidados.

Por fim, chamar a atenção para a importância do Sistema de Informação do Câncer de Mama (SISMAMA), implantado nacionalmente desde junho de 2009, em sua importância de organizar, sistematizar e gerenciar as ações de detecção precoce do câncer de mama, por seu potencial como mecanismo determinante de rastreamento, diagnóstico e controle do câncer

346 Emancipação, Ponta Grossa, 14(2): 337-348, 2014. Disponível em <http://www.revistas2.uepg.br/index.php/emancipacao> 
de mama, permitindo, assim, que a atenção à saúde da mulher realmente seja algo tangível e completo na realidade brasileira.

\section{Referências}

ADER, R.; COHEN, N. The Influence of Conditioning on Immune Response. In: ADER, R.; FELT, D.L.; COHEN, N. Psychoneuroimmunologie. Academic Press. San Diego, 1991.

ALMEIDA, C.M.; LEITE, L. D.; AMORIM, M.H.C. Mulheres mastectomizadas: Avaliação do Stress, Ansiedade e Eventos de Vida. Departamento de Enfermagem, Universidade Federal do Espírito Santo, Vitória, 2000.

ANDERSON, Maria. Atenção Primária. Jornal do povo. 2008. Disponível em: <http://www.esp.ce.gov.br/index. php?option=com_content\&task=view\&id=237>Acesso em: 27 de jul. 2012

ARAÚJO I.M.A., FERNANDES A.F.C. O significado do diagnóstico do câncer de mama para a mulher. Rio de Janeiro: Revista de Enfermagem Anna Nery. n.12, v. 4, p. 664-7, dez 2008.

AMORIM, M.H.C. A Enfermagem e a Psiconeuroimunologia no Câncer de Mama. Tese (Doutorado em Enfermagem), Escola de Enfermagem Anna Nery UFRJ, 1999.

BRASIL. Instituto Nacional do Câncer. Controle do Câncer de Mama: Documento de Consenso. Rio de Janeiro: INCA, 2004.

BRASIL. Instituto Nacional do Câncer. Ações de enfermagem para o controle do câncer: uma proposta de integração ensino-serviço. 3 . $^{\text {a }}$ edição. Revista atualizada e ampliada. Rio de Janeiro: INCA, 2008.

BRASIL. Instituto Nacional do Câncer. Estimativas 2012: incidência de câncer no Brasil. Rio de Janeiro. Disponível em:<http:// www1.inca.gov.br/ estimativa/2012/estimativa20122111.pdf>Acesso em: 19/12/ 2011.

BRASIL. Instituto Nacional do Câncer. Informações Rápidas. Rio de Janeiro, RJ. Disponível em:<http:// www2.inca.gov.br/wps/wcm/connect/cancer/site/ oquee>. Acesso em 20/08/2013

BRASIL b. Instituto Nacional do Câncer. Atlas de Mortalidade por Câncer. Rio de Janeiro. Disponível em: <http://www1.inca.gov.br/estimativa/2012/ estimativa20122111.pdf>. Acesso em 20/08/2013
BERGAMASCO, R. B., ANGELO, M. O sofrimento de descobrir-se com câncer de mama: como o diagnóstico é experienciado pela mulher. Revista Brasileira de Cancerologia, v. 47, n. 3, p. 277-82, 2001.

CAETANO, E. A., GRADIM, C. V. C., SANTOS, L. E. S. Câncer de mama diante do diagnóstico. Revista de Enfermagem, v. 17, n.2, abr/jun; p. 257-61, Rio de Janeiro, 2009.

COHEN, L., HACK, T. F., MOOR, C., KATZ, J., GOSS, P. E. The effects of type of surgery and time on psychological adjustment in women after breast cancer treatment. Ann Surgery Oncology, v. 7, n. 6, p. 427-34, 2000.

DUARTE, T. P.; ANDRADE, A. N. Enfrentando a mastectomia: análise dos relatos de mulheres mastectomizadas sobre questões ligadas à sexualidade. Estudos de Psicologia. v. 8, n. 1, p.155163, 2003.Disponível em: <http://www.scielo.br/pdf/ epsic/v8n1/17245.pdf>. Acesso em: 11 jun. 2013.

FERNANDES, A. F. C.; MAMEDE, M. V. Câncer de mama: mulheres que sobreviveram. Fortaleza (CE): Ed UFC; 2003.

GOFFMAN, E. Estigma: notas sobre a manipulação da identidade deteriorada. $4^{a}$ edição. Rio de Janeiro: Guanabara, 1988.

KENNY, P., KING, M., SHEILL, A., SEYMOUR, J., HALL, J., LANGLANDS, A., et al. Early stage breast cancer: costs and quality of life one year after treatment by mastectomy or conservative surgery and radiation therapy. Breast, USA, v. 9, n. 1, p. 37-44, 2000.

KING, M. T, KENNY, P., SHEIL, A., BOYAGES, H. J. Quality of life three months and one year after first treatment for early stage breast cancer: influence of treatment and patient characteristics. Quality of Life Research, USA, v. 9, p. 789-800. 2000.

HOLZNER, B., KEMMLER, G., KOPP, M., MOSCHEN, R. Quality of life in breast cancer patients-not enough attention for longterm survivors? Psychosomatics, Austria, v. 42, n. 2, p.117-23, 2001. Disponível em: <http://www.ncbi.nlm.nih.gov/pubmed/11239124>. Acesso em: 11 jun. 2013.

MEIHY, J. C. S. B.; HOLANDA, F. História oral: como fazer, como pensar. São Paulo: Contexto, 2007.

NÓRA, M. O. M. História de vida de mulheres mastectomizadas da cidade de Tubarão - SC. 2012. 80f. Dissertação de mestrado apresentada a Escola Superior de Ciências da Santa Casa de Misericórdia de Vitória - EMESCAM. Vitória, Espírito Santo, 2012. 
PIVETTA, M. Câncer, esperanças divididas. Revista Pesquisa FAPESP, São Paulo, SP, n. 98, p.46-53, mai. 2004.

RZEZNIK C.; DALL'AGNOL, C. M. (Re) descobrindo a vida apesar do câncer.Porto Alegre: Revista Gaúcha de Enfermagem, v. 21, n. especial, p. 84-100, 2000.

SILVA, S. E. D. et al. Representações de mulheres mastectomizadas e suas implicações para o autocuidado. Revista Brasileira de Enfermagem, v.63, n. 5, p. 727-34, 2010.

SONTAG, S. A doença como metáfora. Rio de Janeiro: Edições Graal. 1984.

VERAS, R. Fórum. Envelhecimento populacional e as informações de saúde do PNAD: demandas e desafios contemporâneos. Caderno de Saúde Pública, v. 23, n.10, p. 2463-66, 2007.

XAVIER, B. B.; GENTILLI, R. M. L. Afetos e cooperação familiar como coadjuvantes do tratamento de câncer de mama em mulheres. Londrina: Serviço Social em Revista. Programa de Pós-Graduação em Serviço Social e Política Social da Universidade Estadual de Londrina (UEL). v. 14, n. 2, p. 73-95, 2012. 